\title{
Cycle modulation of insulin-like growth factor-binding protein 1 in human endometrium
}

H. Corleta1,2,

E. Capp ${ }^{1,3}$ and

T. Strowitzki ${ }^{4}$

\section{Correspondence \\ H. Corleta \\ Rua Ramiro Barcelos, 910, Cj 905 \\ 90035-001 Porto Alegre, RS \\ Brasil \\ Fax: + 55-51-311-6588 \\ E-mail: hcorleta@portoweb.com.br}

Research supported by FAPERGS.

Received September 21, 1999

Accepted August 7, 2000

\author{
${ }^{1}$ Departamento de O bstetrícia e Ginecologia, \\ Universidade Federal do Rio Grande do Sul, Porto Alegre, RS, Brasil \\ ${ }^{2}$ Clínica Geral de Fertilização Assistida, Porto Alegre, RS, Brasil \\ ${ }^{3}$ Departamento de Fisiologia, Universidade Luterana do Brasil, \\ Porto Alegre, RS, Brasil \\ ${ }^{4}$ Department of Gynecological Endocrinology and Reproductive Medicine, \\ University of H eidelberg, Heidelberg, Germany
}

\section{Abstract}

Endometrium is one of the fastest growing human tissues. Sex hormones, estrogen and progesterone, in interaction with several growth factors, control its growth and differentiation. Insulin-like growth factor 1 (IGF-1) interacts with cell surface receptors and also with specific soluble binding proteins. IGF-binding proteins (IGF-BP) have been shown to modulate IGF-1 action. Of six known isoforms, IGF-BP-1 has been characterized as a marker produced by endometrial stromal cells in the late secretory phase and in the decidua. In the current study, IGF-1-BP concentration and affinity in the proliferative and secretory phase of the menstrual cycle were measured. Endometrial samples were from patients of reproductive age with regular menstrual cycles and taking no steroid hormones. Cytosolic fractions were prepared and binding of ${ }^{125}$ I-labeled IGF-1 performed. Crosslinking reaction products were analyzed by SDS-polyacrylamide gel electrophoresis $(7.5 \%)$ followed by autoradiography. ${ }^{125}$ I-IGF-1 affinity to cytosolic proteins was not statistically different between the proliferative and secretory endometrium. An approximately $35-\mathrm{kDa}$ binding protein was identified when ${ }^{125}$ I-IGF-1 was cross-linked to cytosol proteins. Secretory endometrium had significantly more IGF-1BP when compared to proliferative endometrium. The specificity of the cross-linking process was evaluated by the addition of $100 \mathrm{nM}$ unlabeled IGF-1 or insulin. Unlabeled IGF-1 totally abolished the radioactivity from the band, indicating specific binding. Insulin had no apparent effect on the intensity of the labeled band. These results suggest that IGF-BP could modulate the action of IGF-1 throughout the menstrual cycle. It would be interesting to study this binding protein in other pathologic conditions of the endometrium such as adenocarcinomas and hyperplasia.

\section{Key words}

- IGF-1

- Binding protein

- Endometrium 


\section{Introduction}

Endometrium is one of the fastest growing human tissues. Sex hormones, estrogen and progesterone, in interaction with several growth factors, control its growth and differentiation. Insulin, insulin-like growth factor 1 (IGF-1) and other growth factors have been extensively investigated in recent years. Their expression and activity in human endometrium have been previously described (1).

IGF-1 and insulin receptors show a high degree of structural homology (2). Both are heterotetramers consisting of two $\alpha$ - and two ß-subunits bound by disulfide bridges. The $\alpha$-subunits (MW $135 \mathrm{kDa}$ ), located outside the plasma membrane, are the receptor-binding sites. The $95-\mathrm{kDa} \beta$-subunits are transmembrane proteins with intrinsic kinase activity. Hormone binding triggers a phosphorylation cascade of cellular proteins at tyrosine residues that transmits the growth hormone signal to the metabolic effector systems of the target cell (3-5).

IGF-1, unlike insulin, interacts with cell surface receptors and also with soluble binding proteins specific for IGFs. Insulin-like growth factor-binding proteins (IGF-BPs) have been shown to modulate IGF-1 action. In a variety of tissues IGF-BPs may enhance IGF-1 action $(3,4)$, but this effect has not been reported for endometrial cells. Sexual steroids probably modulate the effects of these growth factors on endometrium. For the IGF-1 signal a modulation of the level of the hormone itself has been demonstrated $(1,6,7)$. In 1993, Strowitzki et al. (7) found that the number of insulin receptors was significantly increased in the secretory phase of the cycle, whereas IGF-1 receptor number and activity appeared to be unaltered in both phases.

Human endometrium is a target organ of ovarian steroids. Estrogen is mitogenic for the endometrium, whereas progesterone blocks and modifies the action of estrogen and changes the proliferative endometrium into a secretory one capable of receiving a fertilized blastocyst. Growth factors are found in abundance during normal ovulatory cycles in this tissue and are associated with cellular proliferation. The modulation of IGF-1 action in endometrial proliferation and differentiation seems to be mediated by IGF-BPs. There are six IGF-BP isoforms (IGF-BP-1 through IGF-BP-6), and their affinities are about two orders of magnitude greater than the affinities of the IGF receptors for the peptide. The IGF-BP-1 is the best characterized binding protein in endometrium, primarily because it is a major protein produced by endometrial stromal cells in the late secretory phase and in the decidua (8). In 1992, IGF-1-dependent tyrosine kinase activity was identified in highly purified membrane preparation from stromal cells of human endometrium in vitro and estrogen and progesterone did not modify the binding and tyrosine kinase activity of the IGF-1 receptor (1). Later it could be demonstrated that in ex vivo endometrium samples obtained either in the proliferative or in the secretory phase of the menstrual cycle IGF-1 signaling is not modulated during the menstrual cycle (7). On the other hand, Rutanen et al. (6) showed a higher IGF-1 binding in the luteal phase.

Whereas the expression of IGF-BP with a maximum in the secretory endometrium has been extensively investigated, no data are available on the affinity of IGF-1 for IGF-BP and its possible modulation throughout the menstrual cycle. In the current study we isolated IGF-1-BP from ex vivo endometrium samples obtained during the proliferative and secretory phase of the menstrual cycle and determined its concentration and affinity for IGF-1 in the phases of the menstrual cycle.

\section{Material and Methods}

\section{Tissue samples}

In the present study, 12 endometrial 
samples were obtained from patients submitted to hysterectomy for reasons not related to this study. All patients were of reproductive age, had regular menstrual cycles, and none was taking any steroid hormones. Six proliferative samples were compared with 6 samples of the secretory phase. One portion of the endometrial tissue was rapidly frozen and stored in liquid nitrogen until further preparation. Endometrial tissues were classified as proliferative or secretory specimens according to the menstrual phase of the patients. Furthermore, histologic examination of all endometria tested was performed retrospectively to confirm classification. All patients gave informed consent to participate in the study.

\section{Preparation of cytosol fractions}

Endometrial tissues were weighed and homogenized with an Ultraturrax blender for 10 to $15 \mathrm{~s}$ at a maximal speed of 20,000 $\mathrm{rpm}$ at $4^{\circ} \mathrm{C}$ in the presence of the protease inhibitors phenylmethyl sulfonyl fluoride (2.5 $\mathrm{mM})$, aprotinin (1,200 trypsin-inhibiting units/l), benzamidine (10 $\mathrm{mM})$, and bacitracin (7,500 U/l) in $25 \mathrm{mM}$ HEPES buffer, $\mathrm{pH}$ 7.4. Subsequently the lysates were centrifuged for $50 \mathrm{~min}$ at $200,000 \mathrm{~g}$ at $4^{\circ} \mathrm{C}$. The supernatant containing the cytosolic fraction was centrifuged for $120 \mathrm{~min}$ at $300 \mathrm{rpm}$ in 2$\mathrm{ml}$ Amicon 10 tubes.

\section{Binding of ${ }^{125}$--labeled IGF-1 to cytosolic proteins}

Cytosolic fractions from 6 proliferative and 6 secretory samples in different concentrations $(0,0.01,0.1,1$, and 2$)$ were incubated with $23 \mathrm{pM}(20,000 \mathrm{cpm}){ }^{125}$ I-IGF-1 for $45 \mathrm{~min}$ at $22^{\circ} \mathrm{C}$ in a solution containing $50 \mathrm{mM}$ Tris- $\mathrm{HCl}, \mathrm{pH} 7.5,10 \mathrm{mM} \mathrm{MgSO}_{4}$, and $1 \%$ BSA. Separation of the free and cytosolic protein-bound ${ }^{125}$ I-IGF-1 was performed using dextran-coated charcoal. The amount of ${ }^{125}$ I-IGF-1 bound to cytosolic pro- tein was determined with a gamma-counter.

\section{Affinity cross-linking of 125 I-IGF-1 to cytosolic proteins}

Cross-linking experiments were performed as previously described (8). Fifty microliters of cytosolic proteins was incubated with $4 \mathrm{mM} \mathrm{MgSO}_{4}, 0.2 \%$ BSA, and $0.5 \mathrm{nM}^{125} \mathrm{I}$-IGF-1 $(450,000 \mathrm{cpm})$ in the presence or absence of $100 \mathrm{nM}$ unlabeled IGF-1 or insulin in a final volume of $80 \mu \mathrm{l}$ for $12 \mathrm{~h}$ at $4{ }^{\circ} \mathrm{C}$. Tubes were chilled on ice, and $3 \mu \mathrm{l}$ of the cross-linking agent DSS $(7 \mathrm{mM}$ in dimethyl sulfoxide) was added for $20 \mathrm{~min}$ at $4^{\circ} \mathrm{C}$. The incubation was terminated by the addition of Laemmli buffer containing 10 $\mathrm{mM}$ dithiothreitol and subsequent boiling for $20 \mathrm{~min}$ at $95^{\circ} \mathrm{C}$. The reaction products were analyzed by SDS-polyacrylamide gel electrophoresis (7.5\%) followed by autoradiography.

\section{Results}

Figure 1 shows the binding of ${ }^{125}$ I-IGF-1 to cytosolic proteins from endometrial tissues. The presence of binding sites for IGF1 could be demonstrated by the increasing binding with cytosolic fractions. The binding (cpm) was higher in the secretory than in

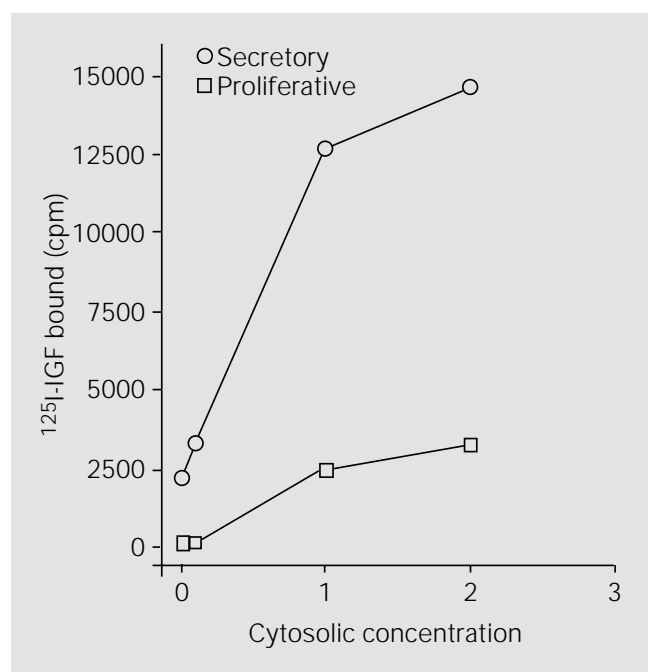

Figure 1 - Different concentrations of cytosolic fractions $(0$, $0.01,0.1,1$, and 2) from 6 proliferative and 6 secretory endometrium specimens were incubated with $23 \mathrm{pM}$ 125/-IGF-1. The binding (cpm) to cytosolic fractions was higher in the secretory (circles) than in the proliferative (squares) endometrium, suggesting the presence of more IGF-BP in the luteal phase. However, the affinity of 125/-IGF-1 for cytosolic proteins was not significantly different between the proliferative and secretory endometrium. 
the proliferative endometrium, suggesting the presence of more IGF-BP in the luteal phase (Figure 1).

To identify molecular weight of the cytosolic protein responsible for the binding with IGF-1 these proteins were affinity labeled with ${ }^{125}$ I-IGF-1 (Figure 2). An approximately 35-kDa binding protein was identified when ${ }^{125}$ I-IGF-1 was cross-linked to cytosol proteins. Secretory endometrium (lanes A-D)

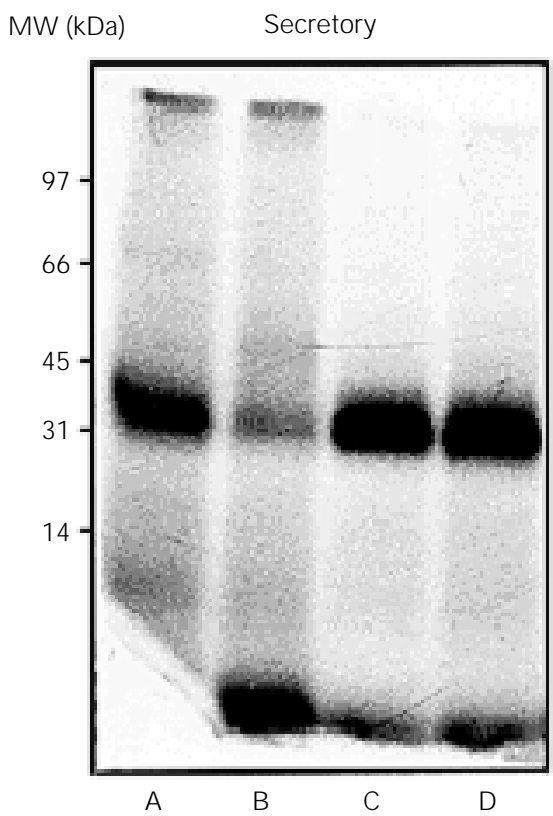

Figure 2 - Autoradiogram of ${ }^{125}$-labeled IGF-1 $(0.5 \mathrm{nM})$ cross-linked to endometrial cytosols prepared from specimens obtained during the secretory (lanes A-D) and proliferative (lanes E-G) phases. Samples were analyzed by SDS-polyacrylamide gel electrophoresis $(7.5 \%)$ under reducing conditions (100 mM dithiothreitol).

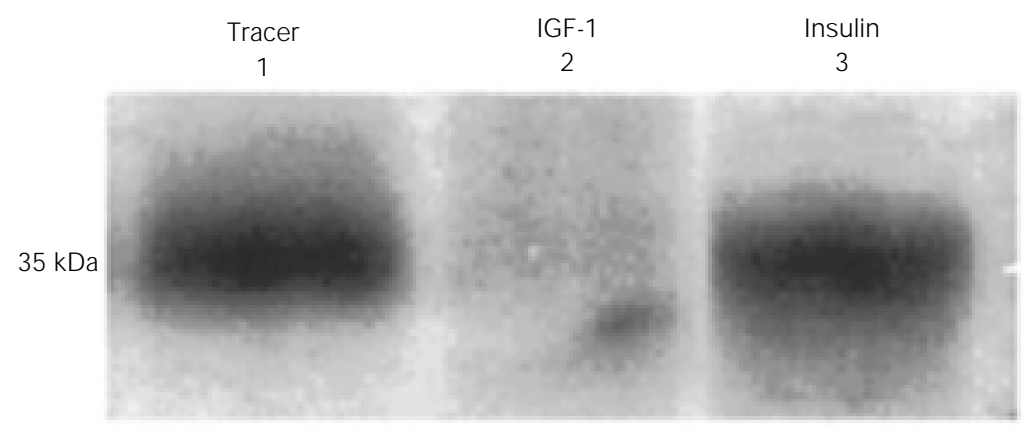

Figure 3 - Cytosolic proteins were incubated with ${ }^{125}$ I-IGF-1 in the absence (lane 1) or presence (lane 2) of unlabeled IGF-1 or insulin (lane 3). Samples were analyzed by SDSpolyacrylamide gel electrophoresis $(7.5 \%)$ under reducing conditions $(100 \mathrm{mM}$ dithiothreitol). had significantly more IGF-1-BP when compared to proliferative endometrium (lanes EG). This was demonstrated in the most intensely labeled band present in secretory endometrium (Figure 2, lanes A-D). The ${ }^{125}$ I-radioactivity incorporation into the 35 $\mathrm{kDa}$ band was greater in the secretory phase $(600.67 \pm 188.58 \mathrm{cpm})$ than in the proliferative phase $(164.00 \pm 60.76 \mathrm{cpm})(\mathrm{P}<0.05)$ of the menstrual cycle. This figure shows that IGF-BPs are present in both cycle phases.

The specificity of the cross-linking process was evaluated (Figure 3 ) by the addition of $100 \mathrm{nM}$ unlabeled IGF-1 or insulin. Unlabeled IGF-1 totally abolished the radioactivity from the band (lane 2), indicating specific binding. Insulin $(100 \mathrm{nM})$ had no apparent effect on the intensity of the labeled band (lane 3).

\section{Discussion}

In previous reports (8), IGF-1 immunoreactive binding proteins were detected in the cytosol of the secretory, but not the proliferative endometrium. In cross-linking of ${ }^{125} \mathrm{I}$ IGF-1 to cytosolic proteins, we also found these binding proteins in proliferative endometria (Figure 2). Our results suggest that human endometrium has cytosolic proteins that specifically bound ${ }^{125}$ I-IGF-1 in both cycle phases, although the concentration of IGF-BP in the secretory phase was higher than in the proliferative phase (Figure 1). This specificity was demonstrated by the increasing binding with concentrated cytosolic proteins, and by the fact that this protein has no affinity for insulin because excess insulin did not abolish the labeled ${ }^{125} \mathrm{I}-$ IGF-1 (Figure 3).

IGFs are believed to have a role in the mitotic and differentiating events observed in human endometrium during the menstrual cycle and in early pregnancy $(5,9)$. IGF-1 activity is altered during the menstrual cycle. Strowitzki et al. (7) demonstrated that the number of IGF-1 receptors is not cycle de- 
pendent. Our results show a cycle-dependent IGF-BP concentration. The incorporation of ${ }^{125}$ I-IGF-1 was significantly higher in the secretory $(600.67 \pm 188.58 \mathrm{cpm})$ than in the proliferative $(164.00 \pm 60.76 \mathrm{cpm})$ endometrium. This helps to answer the question of how the IGF-1 action was modulated, since there was no difference in IGF-1 receptor number in different cycle phases. Progesterone, the main steroid hormone of the secretory phase, seems to play a role in this higher IGF-BP expression and lower IGF-1 bioavailability. We can suppose that IGF-1 has a proliferative action in the first cycle phase and that IGF-BP inhibits IGF-1 binding to its receptor in human secretory endometrium, regulating the proliferative actions of IGF-1 in the second cycle phase. Progesterone enhances 10- to 15-fold the IGF-BP secretion by endometrial stromal cells in vitro, an effect that is blocked by the progesterone antagonist RU486. Insulin, IGF-1 and other growth factors regulated endometrial stromal cells IGF-BP secretion in vitro (10, 11).

In summary, the results of this study suggest that IGF-BP could modulate the action of IGF-1 throughout the menstrual cycle, and its higher concentration in the progestogenic phase may play a role in the implantation process. The IGF-1 bioavailability may be altered by modifications in the IGF-BPs such as glycosylation, phosphorylation and proteolysis that could alter the affinity of IGF-BPs for IGFs. The identification of IGFBPs with specific antibodies also remains to be studied. The expression of IGF-BP-1 in other pathologic conditions like hyperplasia and adenocarcinoma of the endometrium would be interesting to study.

\section{References}

1. Corleta $\mathrm{H}$, Strowitzki $\mathrm{T}$, Kellerer $\mathrm{M}$ \& Häring $H$ (1992). Insulin-like growth factor I-dependent tyrosine kinase activity in stromal cells of human endometrium in vitro. American J ournal of Physiology, 262: 863-868.

2. Shepherd PR \& Kahn BB (1999). Mechanisms of disease: glucose transporters and insulin action - implications for insulin resistance and diabetes mellitus. New England J ournal of Medicine, 341: 248-257.

3. Reynolds R, Talavera F, Roberts J , Hopkins M \& Menon K (1990). Regulation of epidermal growth factor and insulinlike growth factor I receptors by estradiol and progesterone in normal and neoplasic endometrial cell cultures. Gynecological Oncology, 38: 396-406.

4. Pilch PF \& Czech MP (1979). Interaction of crosslinking agents with the insulin effector system of isolated fat cells. J ournal of Biological Chemistry, 254: 3375-3381.

5. Kellerer M, Sesti G, Seffer E, Obermaier-
Kusser B, Pongratz DE, Mosthaf L \& Häring H (1993). Altered pattern of insulin receptor isotypes in skeletal muscle membranes of type 2 (non-insulin-dependent) diabetic subjects. Diabetologia, 36: 628-632.

6. Rutanen E-M, Pekonen F \& Mäkinnen $T$ (1988). Soluble 34K binding protein inhibits the binding of insulin-like growth factor I to its cell receptors in human secretory phase endometrium: evidence for autocrine/paracrine regulation of growth factor action. J ournal of Clinical Endocrinology and Metabolism, 66: 173-180.

7. Strowitzki $T$, Corleta $H$, Kellerer $M$ \& Häring H (1993). Tyrosine kinase activity of insulin-like growth factor I and insulin receptors in human endometrium during the menstrual cycle: cyclic variation of insulin receptor expression. Fertility and Sterility, 59: 315-322.

8. Giudice LC, Duspin BA \& Irwin J C (1992). Steroid and peptide regulation of insulin- like growth factor binding proteins secreted by human endometrial stromal cells is dependent of endometrial differentiation. J ournal of Clinical Endocrinology and Metabolism, 75: 1235-1241.

9. Irwin J C, de las Fuentes LA, Duspin BA \& Giudice LC (1993). Insulin like growth factor regulation of human endometrial stromal cell function: coordinate effects on insulin growth factor binding protein I, cell proliferation and prolactin secretion. Regulatory Peptides, 48: 165-177.

10. Giudice LC (1994). Growth factors and growth modulators in human uterine endometrium: their potential relevance to reproductive medicine. Fertility and Sterility, 61: 1-17.

11. Strowitzki T, Singer G, Rettig I \& Capp E (1996). Characterization of receptors for IGF-1 on cultured human endometrial stromal cells: down-regulation by progesterone. Gynecological Endocrinology, 10: 1-13. 